- Reports 10 year trend findings for non carious tooth conditions in children in the United Kingdom.

- The downward trend of accidental tooth damage continues but the reasons for this are not clear.

- Tooth surface loss continues to be a problem for children in the United Kingdom.

- There is no evidence to suggest that enamel opacities are increasing in children in the United Kingdom.

\title{
The dentinal caries experience of children in the United Kingdom, 2003
}

\author{
N. B. Pitts, ${ }^{1}$ I. G. Chestnutt, ${ }^{2}$ D. Evans, ${ }^{3}$ D. White, ${ }_{1}^{4}$ B. Chadwick ${ }^{5}$ and J. G. Steele ${ }^{6}$
}

\section{CHILDREN'S SURVEY}

1. The dentinal caries experience of children in the United Kingdom, 2003

2. Non-carious tooth conditions in children in the UK, 2003

3. Patterns of care and service use amongst children in the UK, 2003

4. Oral health habits amongst children in the United Kingdom in 2003

5. The reported impact of oral condition on children in the United Kingdom, 2003

6. The orthodontic condition of children in the United Kingdom, 2003

Background The 2003 Children's Dental Health Survey is the fourth in a series of decennial national children's dental health surveys. Aims This paper reports the survey-derived estimates of dentinal caries experience of children aged five, eight, 12 and 15 years, considering the trends over recent decades and the position in 2003 following changes in disease presentation and the use of additional criteria.

Methodology A representative UK sample of children in the four specified age groups were invited to participate in a clinical dental examination in school. A total of 12,698 children were sampled and 10,381 were examined (82\%). Examinations were undertaken in school by trained and calibrated examining teams using reclining chairs and portable lights, the criteria were visual, limited to dentine caries and no diagnostic aids were employed. In order to compare trend data with 1993 and earlier surveys the criteria allowed the reclassification of the full 2003a results (those including cavities and visual dentine caries $-D_{3 c v} M F T / d_{3 c v} m f t$ ) according to the previous criteria to produce results labelled 2003b (those restricted to dentinal cavities - $\mathrm{D}_{3 c} \mathrm{MFT} / \mathrm{d}_{3 c} \mathrm{mft}$ ).

Results and conclusions The experience of obvious dentinal caries in children within the UK has continued to change over the last decade and patterns are different for the two dentitions. While continuing overall improvements are evident for permanent teeth across the UK ( $D_{3 c}$ for 15 -year-old children falling from $42 \%$ in 1983 , via 30\% in 1993 to $13 \%$ in 2003 for example), trends amongst those experiencing dentinal caries are more concerning and there have been no statistically significant improvements for primary teeth (the mean number of teeth with obvious dentine decay $\left(d_{3 c}\right)$ at age five years being 1.3 in 1983 and 1.4 in both 1993 and 2003). The inclusion in the criteria of visual dentinal caries resulted in higher estimates of mean caries and mean caries experience in the permanent dentition (at age 15 years $D_{3}$ increasing from 0.2 to $0.8, D_{3}$ MFT increasing from 1.6 to 2.0 for example) but not the primary dentition (where the estimates for $\% \mathrm{~d}_{3} \mathrm{mft}$ at age five years were identical at $43 \%$ ). Geographic variations also persist across the UK (\% with $D_{3 c v}$ MFT at 12 years being 41\% for England, 54\% Wales, 73\% Northern Ireland and $43 \%$ for the UK; \% with $d_{3 c v}$ mft at age 5 years: $41 \%$ for England, 52\% Wales, 61\% Northern Ireland and 43\% for the UK). These survey results have implications for planning and for daily practice, but must be interpreted carefully acknowledging the specific survey conditions and diagnostic criteria employed.

\section{INTRODUCTION}

The 2003 Children's Dental Health survey, commissioned by the four United Kingdom Health Departments, is the fourth in a series of national surveys of children's oral health that have been carried out since 1973 in England and Wales and in the whole of the UK since 1983. The aim of this paper is to report the survey-derived estimates of dentinal caries experience of children aged five, eight, 12 and 15 years, considering the trends over recent decades and the position in 2003 following 
changes in disease presentation and the use of additional criteria. Other papers in this series report on the non-caries aspects of oral health.

Data on the prevalence and experience of tooth decay (dental caries) in children across the UK population are still seen as a key measure for many parties interested in dentistry, dental and public health, the National Health Service and patients. These results help in measuring both current levels of oral health, as well as in assessing the prospects for future oral health. Further detailed results ${ }^{1}$ which are beyond the scope and space available for this paper can be found at http://www.statistics.gov.uk/children/ dentalhealth/

\section{BACKGROUND}

Before considering the trends seen over recent decades and the results for 2003, it is important to understand the contemporary context of dental caries - which is now seen as a dynamic disease process with a number of stages ${ }^{2}-$ and to appreciate that there are a number of technical issues in both survey and clinical settings around making valid clinical measurement of caries appropriate to modern preventive care. ${ }^{3-5}$ The disease process is initially reversible and the twin aims of preventive caries management are to prevent new disease in susceptible groups and individuals and to control lesions effectively when they do occur. ${ }^{4,5}$ Consequently in the second millennium we are concerned with more than just cavities in teeth; we do, however, need to understand the current caries position, particularly when benchmarked against caries estimates from previous decades.

The conventions for clinical caries assessment have been evolving over the last decade to maintain so-called 'backwards compatibility' with earlier surveys while introducing enhancements to survey methodology which allow more appropriate estimates of caries prevalence to be made. ${ }^{6,7}$ Apparently trivial differences in diagnostic criteria may produce clinically signif-

Fig. 1 Diagnostic criteria conventions for dentine caries employed in 2003

\section{Criteria (2003a)}

Decay into dentine (D3cor d3cv)

All teeth with cavitated or visual dentine caries present and teeth that had restorations with visual and cavitated dentine caries. Excludes teeth with enamel caries present. Permanent teeth with decay into dentine are assumed to be those that are currently in need of operative treatment. (In primary teeth the decision as to whether to fill, review or extract such teeth would be taken in the knowledge that they will exfoliate naturally at some point in the future.)

\section{Obvious decay experience (D3crMFT)}

All teeth with cavitated or visual dentine caries, restorations with cavitated or visual dentine caries, teeth with filled decay (otherwise sound) and teeth extracted due to caries. Excludes teeth with enamel caries present. The term obvious decay experience relates to teeth with dentinal cavities, missing teeth and filled teeth in the DMFT dental decay index. icant differences in the results ${ }^{8,9}$ which may in any case be different to those obtained from a typical dental examination in daily practice. The standardised training of examining teams in surveys is therefore both important and challenging.

\section{METHODOLOGY}

Full details of the methodology, clinical criteria, sampling technique and the weighting procedures used in the survey are

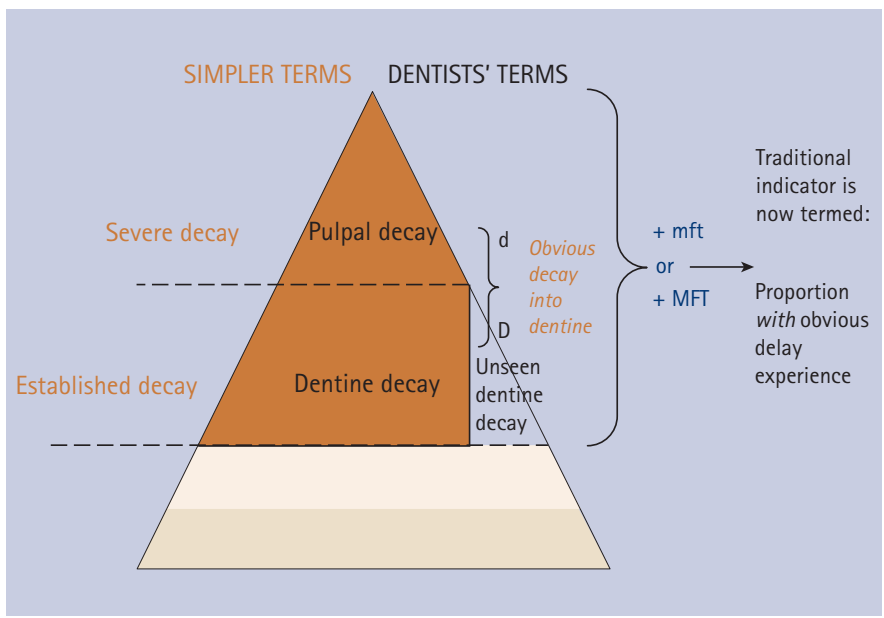

Fig.2a Recording caries at the dentine level - Contemporary terms 1 Adapted from Pitts N B. Community Dental Health 2004;21: 193-198.

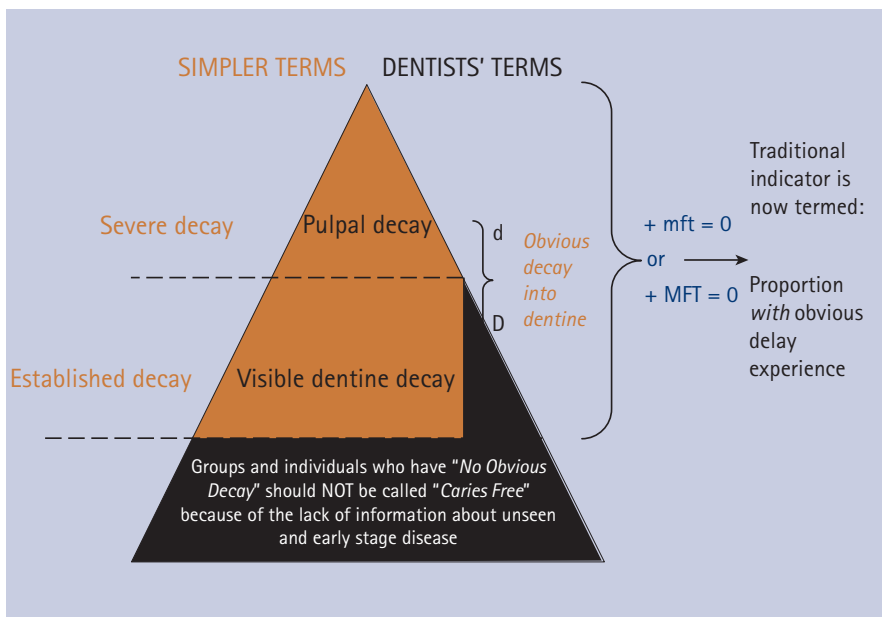

Fig.2b Recording caries at the dentine level - Contemporary terms 2 Adapted from Pitts N B. Community Dental Health 2004; 21: 193-198.

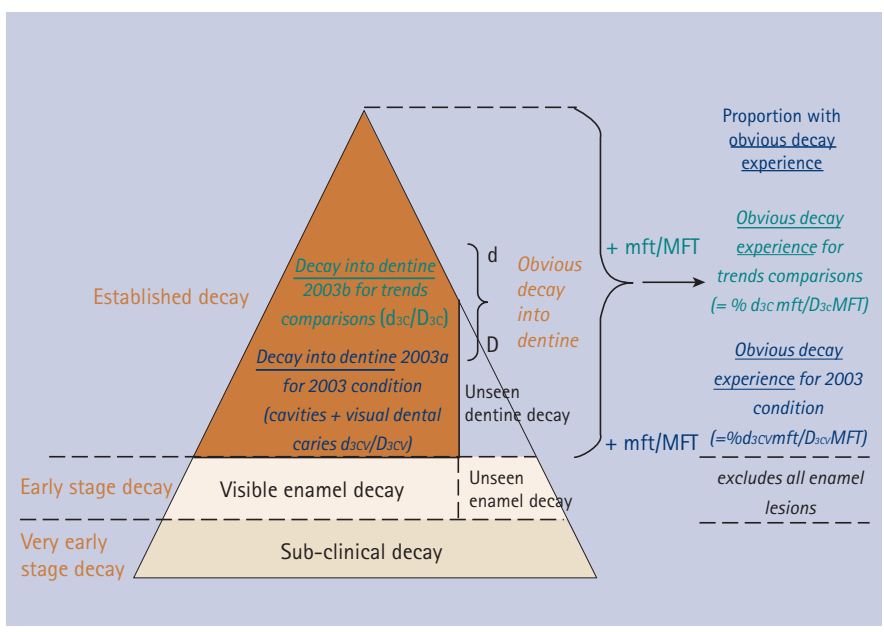

Fig.2c Recording caries at the dentine level - Contemporary terms 3 Adapted from Pitts N B. Community Dental Health 2004 ;21: 193-198. 
described elsewhere. ${ }^{1,9}$ In summary, the 2003 survey was based on a representative sample of children aged five, eight, 12 and 15 years attending government maintained and independent schools in the UK who were invited to participate in a clinical dental examination in school. A total of 12,698 children were sampled and 10,381 were examined (82\%). Examinations were undertaken in school by trained examining teams using reclining chairs and portable lights; the caries criteria were visual and limited to dentine lesions, and no diagnostic aids were employed. The training required teams to study a specially prepared interactive CD-ROM prior to attending a two day residential training course which included discussion and review of the training material as well as discussion of clinical cases, before ending with a calibration exercise.

In the 2003 survey, the criteria for assessing dental caries were changed from those used in the earlier surveys to reflect changes in the presentation of dentine decay. In order to compare the data on the condition of teeth in 2003 with those from 1993 and earlier surveys, the full '2003a' data were re-classified according to the pre-2003 criteria to produce a second set of '2003b' results (see Fig. 1 for details of the two sets of criteria employed). Where this report refers to trends in decay over time, the conditions of children's teeth are reported from the $2003 \mathrm{~b}$ results. The reports of the overall condition of children's teeth in 2003 are derived from the 2003a results. In all cases clinical caries visible in enamel was excluded.

The three graphics in Figure 2 show the iceberg metaphor, familiar to many in cariology but less well known in primary dental care, for different stages of dental caries reported or excluded in traditional surveys. It also sets out contemporary survey terminology for recording caries at the dentinal level. Figure 2a shows the convention used in this survey for determining the decayed $(d / D)$ component of the caries index used. Adding the missing $(\mathrm{m} / \mathrm{M})$ and filled $(\mathrm{f} / \mathrm{F})$ components allows the caries experience by tooth (dmft/DMFT) and the proportion affected to be calculated for the primary and permanent teeth respectively. Clarity is needed in discussing and reporting these stages of decay to ensure that patient care, policy direction and the evolving evidence base are more clearly aligned. ${ }^{5}$ Figure $2 \mathrm{~b}$ is a diagrammatic representation of the rather limited part of the total caries process which is captured by classical dental epidemiological survey criteria. It demonstrates the inappropriateness of using the term 'caries free' when reporting results from surveys recording only caries into dentine, which is why there is now a move away from this term and towards referring to the proportion of children "with no obvious decay' in order to be clearer to all parties, including patients and the public. Figure $2 c$ shows graphically the differences between the 2003a and 2003b criteria. Further details of the methodology can be found in the Child Dental Health 2003 Technical Report. ${ }^{9}$

In view of the complexity of the sampling design and resultant weighting procedures, sampling errors were quantified using the statistics programme STATA, and were calculated using a design factor (deft) to take account of the complex sampling and weighting procedures. The statistical significances of differences in means and percentages between sub groups were tested by calculating the confidence interval for the differences observed, based on the standard errors calculated using the design factor. This ensured that sampling error was taken into account in the testing procedure. Where statistically significant differences between groups are reported, the $5 \%$ threshold $(p<0.05)$ was used. Further details of sampling, response, examination protocols and statistical methods can be found elsewhere. ${ }^{9}$

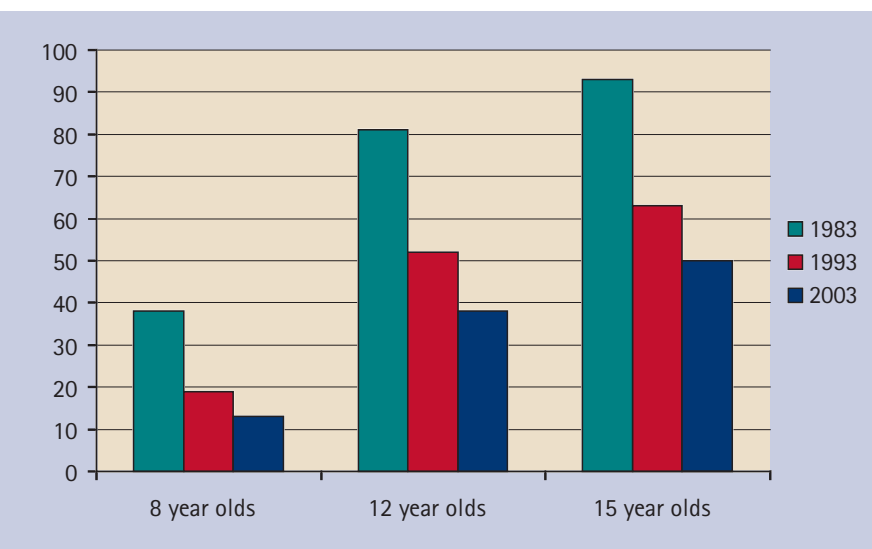

Fig. 3 Proportion of UK children with obvious decay experience in permanent teeth 1983-2003 ( $\left.D_{3 c} M F T\right)$

Table 1 Proportion of children with obvious decay experience in permanent teeth by age (United Kingdom, 1983, 1993, 2003b = D3cMFT)

\begin{tabular}{|c|c|c|c|}
\hline & $\begin{array}{l}\text { Age } \\
8(\%)\end{array}$ & $12(\%)$ & $15(\%)$ \\
\hline \multicolumn{4}{|c|}{ Decay into dentine } \\
\hline 1983 & 19 & 32 & 42 \\
\hline 1993 & 12 & 24 & 30 \\
\hline $2003 b$ & 7 & 12 & 13 \\
\hline \multicolumn{4}{|c|}{ Filled (otherwise sound) } \\
\hline 1983 & 25 & 69 & 85 \\
\hline 1993 & 8 & 39 & 52 \\
\hline $2003 b$ & 7 & 26 & 42 \\
\hline \multicolumn{4}{|c|}{ Obvious decay experience } \\
\hline 1983 & 38 & 81 & 93 \\
\hline 1993 & 19 & 52 & 63 \\
\hline $2003 b$ & 14 & 34 & 49 \\
\hline
\end{tabular}

Table 2 Mean number of permanent teeth with obvious decay experience by age (United Kingdom, 1983, 1993, 2003b = D $_{3 c} M F T$ )

\begin{tabular}{|c|c|c|c|}
\hline & $\begin{array}{l}\text { Age } \\
8 \\
\text { Mea }\end{array}$ & $\begin{array}{c}12 \\
f \text { teet }\end{array}$ & 15 \\
\hline \multicolumn{4}{|c|}{ Decay into dentine } \\
\hline 1983 & 0.3 & 0.6 & 1.0 \\
\hline 1993 & 0.2 & 0.4 & 0.7 \\
\hline $2003 b$ & 0.1 & 0.2 & 0. \\
\hline \multicolumn{4}{|c|}{ Filled (otherwise sound) } \\
\hline 1983 & 0.5 & 2.1 & 4.4 \\
\hline 1993 & 0.1 & 0.8 & 1.7 \\
\hline $2003 b$ & 0.1 & 0.5 & 1.2 \\
\hline \multicolumn{4}{|c|}{ Obvious decay experience } \\
\hline 1983 & 0.8 & 3.1 & 5.9 \\
\hline 1993 & 0.4 & 1.4 & 2.5 \\
\hline $2003 b$ & 0.2 & 0.8 & 1.6 \\
\hline
\end{tabular}

Table 3 Mean number of permanent teeth with obvious decay experience in children with obvious decay experience by age (United Kingdom, 1993, $2003 b=D_{3 c}$ MFT)

\begin{tabular}{|c|c|c|c|}
\hline & $\begin{array}{l}\text { Age } \\
\mathbf{8} \\
\text { Mea }\end{array}$ & $\begin{aligned} & 12 \\
= & \text { teeth }\end{aligned}$ & 15 \\
\hline \multicolumn{4}{|c|}{ Decay into dentine } \\
\hline 1993 & 1 & 0.8 & 1.0 \\
\hline $2003 b$ & 0.7 & 0.5 & 0.5 \\
\hline \multicolumn{4}{|c|}{ Filled (otherwise sound) } \\
\hline 1993 & 0.7 & 1.6 & 2.7 \\
\hline $2003 b$ & 0.5 & 1.2 & 1.3 \\
\hline \multicolumn{4}{|c|}{ Obvious decay experience } \\
\hline 1993 & 1.9 & 2.7 & 4.0 \\
\hline $2003 b$ & 1.8 & 2.5 & 3.2 \\
\hline
\end{tabular}




\section{RESULTS}

\section{Trend data for caries using historical criteria Permanent teeth}

These results (using the pre-2003 criteria) show improvements in the caries status of permanent teeth in the older children. Consistent evidence of improvements in both the mean caries estimates and the pattern of care are seen. It is, however, important not to be complacent, particularly as the mean values for those individuals who already exhibit some disease experience at this diagnostic level represent a sizeable clinical

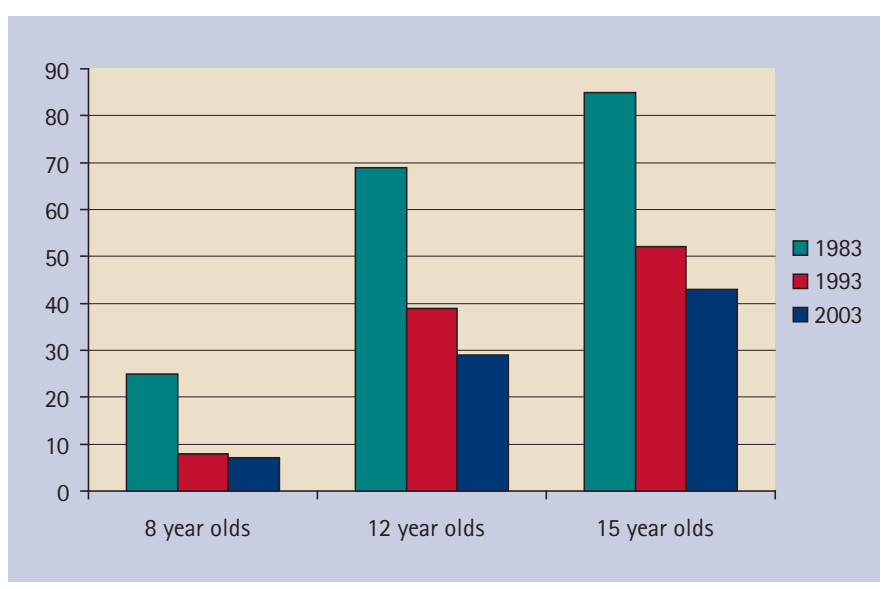

Fig. 4 Proportion of obvious decay experience in UK children which is filled permanent teeth

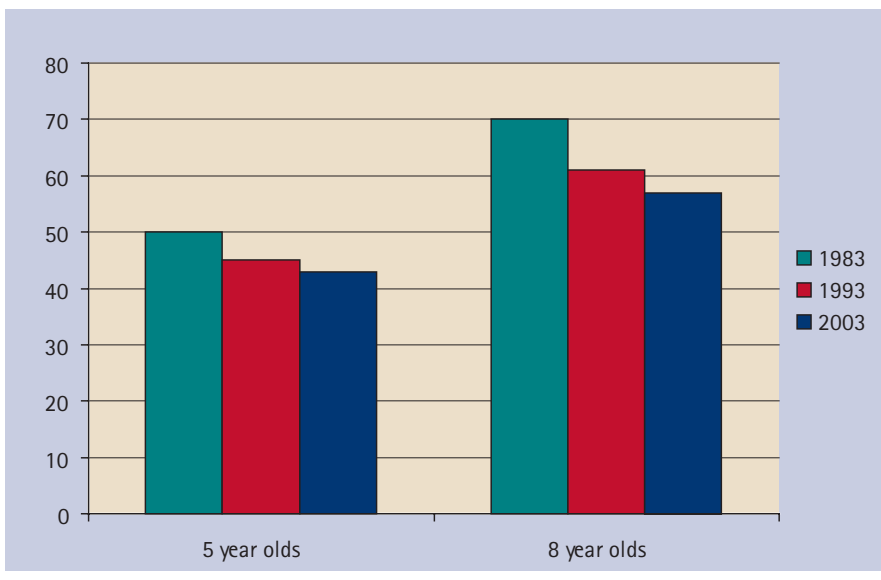

Fig. 5 Proportion of UK children with obvious decay experience in primary teeth $\left(\mathrm{d}_{3 \mathrm{c}} \mathrm{mft}\right)$

Table 4 Proportion of children with obvious decay experience in primary teeth by age (United Kingdom, 1983, 1993, 2003b $=d_{3 c} \mathrm{mft}$ )

\begin{tabular}{lll} 
& $\begin{array}{l}\text { Age } \\
\mathbf{5} \\
\text { Percentage of children: }\end{array}$ & $\mathbf{8}$ \\
& & \\
\hline Decay into dentine & 41 & 49 \\
1983 & 40 & 50 \\
1993 & 40 & 50 \\
$2003 b$ & & \\
Filled (otherwise sound) & 23 & 47 \\
1983 & 15 & 33 \\
1993 & 12 & 26 \\
$2003 b$ & & \\
Obvious decay experience & 50 & 70 \\
1983 & 45 & 61 \\
1993 & 43 & 57 \\
$2003 b$ & &
\end{tabular}

burden and those at the 'tail' of the distribution still show high average levels of obvious dentine decay.

In permanent teeth, the proportion of eight, 12 and 15-yearolds with decay into dentine $\left(\mathrm{D}_{3 \mathrm{c}}\right)$ and with obvious decay experience $\left(\mathrm{D}_{3 \mathrm{c}} \mathrm{MFT}\right)$ has decreased significantly since 1983 (see Fig. 3 and Table 1). The percentage point fall was particularly pronounced in the proportion of 15-year-olds with decay into dentine $\left(\mathrm{D}_{3 \mathrm{c}}\right): 42 \%$ in 1983, 30\% in 1993 and 13\% in 2003. In 2003, $66 \%$ of 12 -year-olds and $51 \%$ of 15 -year-olds had no obvious decay experience $\left(\mathrm{D}_{3 \mathrm{c}} \mathrm{MFT}\right) .{ }^{1}$ The average number of permanent teeth with decay into dentine $\left(\mathrm{D}_{3 \mathrm{c}}\right)$ or obvious decay experience $\left(\mathrm{D}_{3 \mathrm{c}}\right.$ MFT) among eight, 12 and 15-year-olds are set out in Table 2 and show decreases between the 1983, 1993 and 2003 surveys. When results for those children who have the problem of obvious dentine caries are examined separately (Table 3), the average values for individuals are more similar to those seen in previous decades and become more clinically meaningful.

Table 5 Mean number of primary teeth with obvious decay experience by age (United Kingdom, 1983, 1993, 2003b $=\mathrm{d}_{3 \mathrm{c}} \mathrm{mft}$ )

\begin{tabular}{lll}
\hline & $\begin{array}{l}\text { Age } \\
\mathbf{5} \\
\text { Mean number of teeth: }\end{array}$ & $\mathbf{8}$ \\
& & \\
\hline Decay into dentine & 1.3 & 1.2 \\
1983 & 1.4 & 1.3 \\
1993 & 1.4 & 1.3 \\
$2003 b$ & & \\
Filled (otherwise sound) & 0.5 & 1.2 \\
1983 & 0.3 & 0.7 \\
1993 & 0.2 & 0.5 \\
2003b & & \\
Obvious decay experience & 1.8 & 2.3 \\
1983 & 1.7 & 2.0 \\
1993 & 1.6 & 1.8 \\
2003b & &
\end{tabular}

The overall fall in obvious caries experience was complemented by a significant decrease in the proportion of 12 and 15-year-olds with filled permanent teeth (Fig. 4). Although the average number of filled permanent teeth also decreased among 12 and 15-year-olds, the proportion of the total obvious decay experience represented by filled teeth among eight, 12 and 15-year-olds has increased since 1993, indicating a relative increase in restorative care in permanent teeth in children.

\section{Primary teeth}

There were no statistically significant changes between the 1993 and 2003 surveys in the proportion of five and eightyear-olds with obvious decay experience $\left(\mathrm{d}_{3 \mathrm{c}} \mathrm{mft}\right)$, or in the proportion having decay into dentine $\left(\mathrm{d}_{3 \mathrm{c}}\right)$, in the primary teeth (see Fig. 5 and Table 4).

The proportion of five and eight-year-olds with filled primary teeth has declined significantly since 1983 . In both five and eight-year-olds, filled primary teeth represented a smaller proportion of the total obvious decay experience than in the previous surveys. This indicates an overall decline in restorative care at a time when the oral health of younger children is not improving. The average number of filled primary teeth in five and eight-year-olds has also fallen since 1983 (see Table 5).

This age group is seen as the best with which to discern early-on current health trends as the results are not confounded by an overlay of the historical outcomes of past disease activity, which is seen in the older age groups. The burden of disease in those most affected ${ }^{1}$ is again a significant issue and the inequalities between the best and the worst groupings are stark. 
Table 6 Proportion with obvious decay in permanent teeth at ages eight, 12 and 15 years with both the 2003a and 2003b diagnostic criteria.

\begin{tabular}{llll}
\hline & $\begin{array}{l}\text { Age } \\
\mathbf{8}\end{array}$ & \multicolumn{1}{c}{$\mathbf{1 2}$} & \\
& Percentage of children: & \\
& & & \\
\hline $\begin{array}{lll}\text { Decay into dentine } \\
2003 a+\end{array}$ & 14 & 29 & 32 \\
$2003 b++$ & 7 & 12 & 13 \\
Obvious decay experience & & & \\
$2003 a+$ & 19 & 43 & 57 \\
$2003 b++$ & 14 & 34 & 49 \\
\hline
\end{tabular}

+Criteria used for 2003 survey (D3crMF includes visual caries)

++Criteria used for 1993 survey (D3cMFT excludes visual caries)

Table 7 Mean number of permanent teeth with obvious decay at ages eight, 12 and 15 years with both the 2003a and 2003b diagnostic criteria.

\begin{tabular}{|c|c|c|c|}
\hline & $\begin{array}{l}\text { Age } \\
8 \\
\text { Mea }\end{array}$ & $\begin{array}{l}12 \\
\text { teeth }\end{array}$ & 15 \\
\hline \multicolumn{4}{|c|}{ Decay into dentine } \\
\hline $2003 a+$ & 0.2 & 0.5 & 0.8 \\
\hline $2003 b++$ & 0.1 & 0.2 & 0.2 \\
\hline \multicolumn{4}{|c|}{ Obvious decay experience } \\
\hline $2003 a+$ & 0.3 & 1.1 & 2.0 \\
\hline $2003 b++$ & 0.2 & 0.8 & 1.6 \\
\hline
\end{tabular}

Table 8 Mean number of permanent teeth with obvious decay among those with decay experience at ages eight, 12 and 15 years with both the 2003a and $2003 \mathrm{~b}$ diagnostic criteria.

\begin{tabular}{|c|c|c|c|}
\hline & $\begin{array}{l}\text { Age } \\
8 \\
\text { Mea }\end{array}$ & $\begin{array}{c}12 \\
\text { f teeth }\end{array}$ & 15 \\
\hline \multicolumn{4}{|c|}{ Decay into dentine } \\
\hline $2003 a+$ & 1.2 & 1.2 & \\
\hline $2003 b++$ & 0.7 & 0.5 & 0.5 \\
\hline \multicolumn{4}{|c|}{ Obvious decay experience } \\
\hline $2003 a+$ & 1.8 & 2.5 & 3.6 \\
\hline $2003 b++$ & 1.6 & 2.3 & 3.2 \\
\hline
\end{tabular}

Table 9 Proportion with obvious decay in primary teeth at ages five and eight years with both the 2003a and 2003b diagnostic criteria.

\begin{tabular}{|c|c|c|}
\hline & $\begin{array}{l}\text { Age } \\
5 \\
\text { Percentage of children: }\end{array}$ & 8 \\
\hline \multicolumn{3}{|c|}{ Decay into dentine } \\
\hline $2003 a+$ & 40 & 51 \\
\hline $2003 b++$ & 40 & 50 \\
\hline \multicolumn{3}{|c|}{ Obvious decay experience } \\
\hline $2003 a+$ & 43 & 57 \\
\hline $2003 b++$ & 43 & 57 \\
\hline
\end{tabular}

\section{Changes in dentinal decay and disease presentation} Impact of collecting data on visual dentine caries

In the permanent dentition, use of the contemporary visual criteria in 2003 (as compared to results computed according to the criteria used in previous decades) resulted in sizeable changes to the results. For example, among 12-year-olds the proportion of children with obvious decay experience in 2003
Table 10a Proportion of children with obvious decay experience ( $\left.D_{3 c v} M F T\right)$ in permanent teeth by country and age (United Kingdom, 2003a)

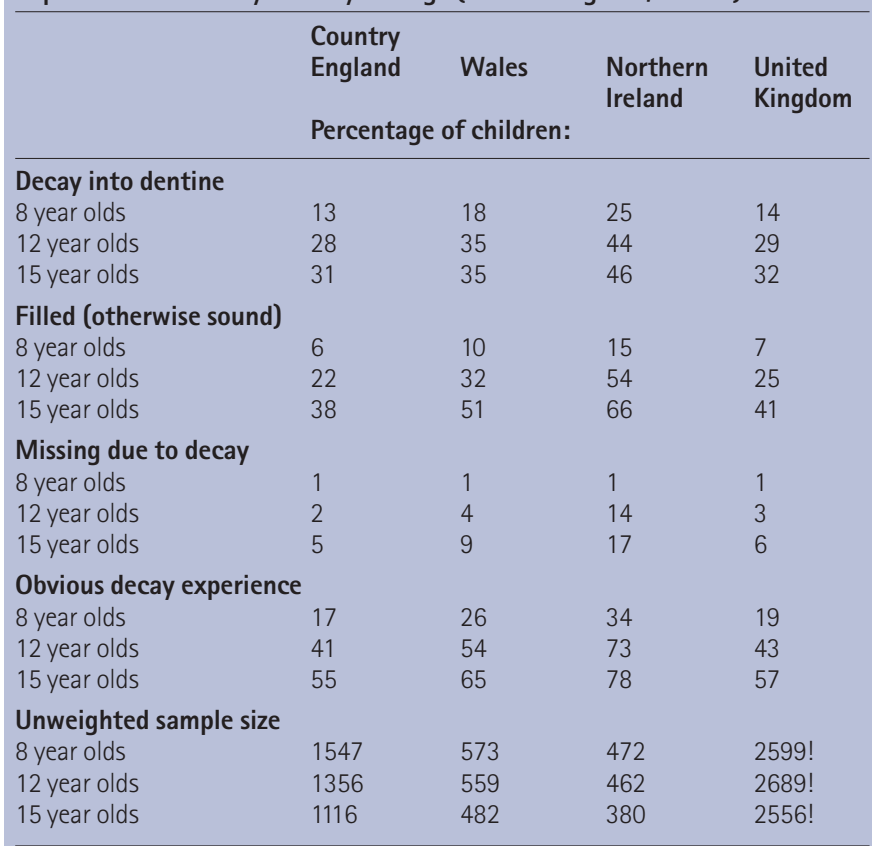

!Weighted bases presented for UK

Table 10b Mean number of permanent teeth with obvious decay experience ( $D_{3 \mathrm{cv}}$ MFT) by country and age (United Kingdom, 2003a)

\begin{tabular}{|c|c|c|c|c|}
\hline & $\begin{array}{l}\text { Country } \\
\text { England } \\
\text { Mean nur }\end{array}$ & $\begin{array}{l}\text { Wales } \\
\text { er of per }\end{array}$ & $\begin{array}{l}\text { Northern } \\
\text { Ireland } \\
\text { ent teeth: }\end{array}$ & $\begin{array}{l}\text { United } \\
\text { Kingdom }\end{array}$ \\
\hline \multicolumn{5}{|c|}{ Decay into dentine } \\
\hline 8 year olds & 0.2 & 0.3 & 0.5 & 0.2 \\
\hline 12 year olds & 0.5 & 0.7 & 1.1 & 0.5 \\
\hline 15 year olds & 0.8 & 0.8 & 1.2 & 0.8 \\
\hline \multicolumn{5}{|c|}{ Filled (otherwise sound) } \\
\hline 8 year olds & 0.1 & 0.1 & 0.3 & 0.1 \\
\hline 12 year olds & 0.4 & 0.6 & 1.4 & 0.5 \\
\hline 15 year olds & 1.0 & 1.5 & 2.8 & 1.2 \\
\hline \multicolumn{5}{|c|}{ Missing due to decay } \\
\hline 8 year olds & $*$ & * & * & * \\
\hline 12 year olds & * & 0.1 & 0.3 & * \\
\hline 15 year olds & 0.1 & 0.2 & 0.4 & 0.1 \\
\hline \multicolumn{5}{|c|}{ Obvious decay experience } \\
\hline 8 year olds & 0.3 & 0.5 & 0.8 & 0.3 \\
\hline 12 year olds & 1.0 & 1.4 & 2.7 & 1.1 \\
\hline 15 year olds & 1.8 & 2.5 & 4.4 & 2.0 \\
\hline
\end{tabular}

increased from $34 \%$ to $43 \%$, the proportion with decay into dentine in 2003 increased from 12\% to 29\% (Table 6), the mean number of teeth with obvious decay experience in 2003 increased from 0.8 to 1.1 and the mean number of teeth with decay into dentine in 2003 increased from 0.2 to 0.5 (Table 7). A similar effect with large increases in the mean number of permanent teeth assessed as being affected by obvious dentine caries was also seen on the mean values for those who already had some dentinal decay experience in 2003 (Table 8).

In the primary dentition, use of the contemporary criteria including visual dentine caries in $2003\left(\mathrm{~d}_{3 \mathrm{cv}}\right.$ and $\left.\mathrm{d}_{3 \mathrm{cv}} \mathrm{mft}\right)$ resulted in little or no change to the estimated proportion of children (Table 9), or the mean number of teeth affected. ${ }^{1}$

\section{The dentine caries situation in children in the UK in 2003}

The 2003a results (with visual dentine caries included) should provide more contemporary estimates of dentine caries expe- 


\begin{tabular}{|c|c|c|c|c|}
\hline & $\begin{array}{l}\text { Country } \\
\text { England } \\
\text { Percenta }\end{array}$ & $\begin{array}{l}\text { Wales } \\
\text { of children: }\end{array}$ & $\begin{array}{l}\text { Northern } \\
\text { Ireland }\end{array}$ & $\begin{array}{l}\text { United } \\
\text { Kingdom }\end{array}$ \\
\hline $\begin{array}{l}\text { Decay into dentine } \\
5 \text { year olds } \\
8 \text { year olds }\end{array}$ & $\begin{array}{l}38 \\
48\end{array}$ & $\begin{array}{l}48 \\
64\end{array}$ & $\begin{array}{l}57 \\
70\end{array}$ & $\begin{array}{l}40 \\
51\end{array}$ \\
\hline $\begin{array}{l}\text { Filled (otherwise sound) } \\
5 \text { year olds } \\
8 \text { year olds }\end{array}$ & $\begin{array}{l}10 \\
22\end{array}$ & $\begin{array}{l}15 \\
32\end{array}$ & $\begin{array}{l}19 \\
34\end{array}$ & $\begin{array}{l}11 \\
24\end{array}$ \\
\hline $\begin{array}{l}\text { Obvious decay experience } \\
5 \text { year olds } \\
8 \text { year olds }\end{array}$ & $\begin{array}{l}41 \\
54\end{array}$ & $\begin{array}{l}52 \\
71\end{array}$ & $\begin{array}{l}61 \\
76\end{array}$ & $\begin{array}{l}43 \\
57\end{array}$ \\
\hline $\begin{array}{l}\text { Unweighted sample size } \\
5 \text { year olds } \\
8 \text { year olds }\end{array}$ & $\begin{array}{l}1620 \\
1547\end{array}$ & $\begin{array}{l}582 \\
573\end{array}$ & $\begin{array}{l}456 \\
462\end{array}$ & $\begin{array}{l}2538 ! \\
2599 !\end{array}$ \\
\hline
\end{tabular}

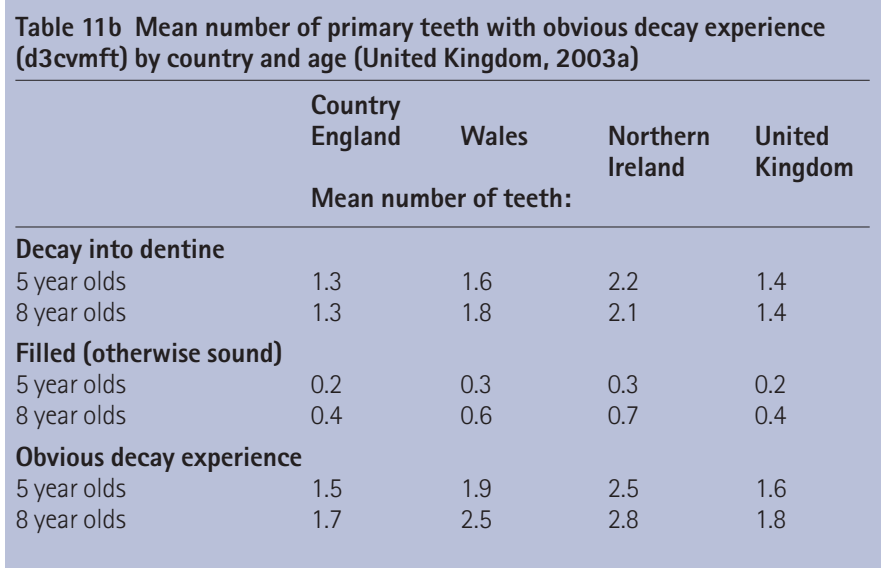

rience from the standpoint of a visual survey examination without diagnostic aids than the previous surveys. Including visual dentine caries in surveys is not new; BASCD-coordinated NHS surveys have used this type of criteria since $1992^{4}$ and they were also employed in the 1998 UK Adult Dental Health Survey. It should be remembered that all these estimates exclude all caries visible in the enamel that clinicians routinely score and which are the focus of secondary preventive care. $^{3}$

Table 10a sets out mean values for proportion of children in the United Kingdom with obvious decay experience $\left(D_{3 \mathrm{cv}} \mathrm{MFT}\right)$ in permanent teeth by 'country' and age; Table $10 \mathrm{~b}$ sets out the mean number of permanent teeth with obvious decay experience $\left(D_{3 c v} M F T\right)$ by age across the United Kingdom (note that sampling for Scotland precluded the provision of separate results for Scotland).

Table 11a shows the proportion of UK children with obvious decay experience $\left(\mathrm{d}_{3 \mathrm{cv}} \mathrm{mft}\right)$ in primary teeth by country and age while Table 11b shows the mean number of primary teeth with obvious decay experience $\left(\mathrm{d}_{3 \mathrm{cv}} \mathrm{mft}\right)$ by country and age.

Variation in levels of decay was again found among children in England, Wales and Northern Ireland in both primary and permanent teeth. There was also evidence of some variation in levels of decay across geographic regions in England and Wales. ${ }^{1}$

Among permanent teeth, a lower proportion of eight, 12 and 15-year-olds in England had obvious decay experience $\left(D_{3 c v}\right.$ MFT) than in Northern Ireland and Wales. The average number of permanent teeth with obvious decay experience
$\left(D_{3 \mathrm{cv}}\right.$ MFT) was lower in England than in Wales or Northern Ireland in all age groups. The proportion with $\mathrm{D}_{3 \mathrm{cv}}$ MFT at age 12 years being 41\% for England, 54\% Wales, 73\% Northern Ireland and $43 \%$ for the UK. The proportion of five and eightyear-olds with obvious decay experience $\left(\mathrm{d}_{3 \mathrm{cv}} \mathrm{mft}\right)$ was lower in England than in Wales or Northern Ireland (41\% for England, 52\% Wales, 61\% Northern Ireland and 43\% for the UK) and the average number of teeth affected by decay was also lowest in England.

\section{DISCUSSION}

\section{What the survey provides}

This survey provides unique national data on historical trends and current status of obvious dentine caries for a representative group of over 10,000 UK children who were examined clinically. The attainment of an $82 \%$ response rate is a significant achievement for this type of survey requiring as it does access to children in school, a comprehensive examination incorporating both caries and other conditions and linkage to an extensive questionnaire. The results of the survey complement the more local but limited data obtained more frequently from BASCD/NHS dental epidemiology programme. ${ }^{10}$

These UK 'average' results are becoming more important for everyday primary care dentistry, where knowing accurate population estimates of the caries levels for each age group on a UK, country, or regional basis provides a yardstick with which to assess caries in the specific groups of children who attend a practice or clinic. It is increasingly important for many dentists to understand these comparisons as moves to local contracting and oral health improvement are introduced into the NHS in many parts of the UK.

\section{Information on trends over decades and its implications}

The information on trends over time will help individual clinicians better understand the changes that are taking place within patient groups. Improvements can be expected in permanent teeth in many older children, but the dentist must still be vigilant for the higher levels of dentinal decay still found in those affected. Caries patterns in these groups remain a concern. In order to respond to the greater cariogenic challenge in these patients a decreased recall frequency accompanied by more aggressive preventive interventions will often be appropriate, as detailed in the recent NICE guidance. ${ }^{11}$ It is, however, challenging that this change in the pattern of disease comes at a time of diagnostic difficulties in finding 'hidden' dentine caries in permanent teeth following the change in presentation of caries in this age group (see below).

The trends information for primary teeth in five-year-old children, often held to be the most sensitive barometer of change, is flat - showing no overall improvement. The implications for this age group are that more effort is needed to regain the continuing oral health improvements seen previously, whether this is at a practice, community or country level. There is: a need for 'upstream' public health interventions to better control this preventable disease by primary prevention, for example by increasing the availability of fluoride; a need for effective oral health promotion (which should be linked to general health promotion) which should address improving diet and hygiene; and a need to acknowledge the different health needs of different geographical areas and population sub-groups. ${ }^{1}$ At the dental primary care level there is a need for complementary initiatives such as a more 'joined-up' dental and wider primary care approach, with effective interventions for the youngest children before they ever attend the current clinical dental services. In addition, there is a need for 
child-friendly, preventively oriented and clinically effective dental services to be available to children. These services should particularly (but not exclusively) cater for those with high levels of caries and who are at high caries risk. Lower risk individuals are, however, not immune from developing new lesions and can change risk group as they change health behaviours.

\section{The evolution of diagnostic criteria and its impact}

The need for the change made in the diagnostic criteria used in recent national surveys and the implications which flow from them should be understood by those in general practice and primary care. It is important to understand the very real challenges associated with reporting oral health trends over decades $^{12}$ as disease presentation, survey methodology and scientific understanding all change over these periods. The diagnostic criteria evolved ${ }^{1,6,7,9}$ in response to concerns from survey organisers and from examiners about dentine lesions with clinically obvious shadows producing grey discolorations below enamel surfaces, but which did not show classical 'cavities'. The worry was that such surfaces should not be classified as 'sound' in a survey setting when they would be scored 'dentine caries' by the same examiner in a clinic or surgery. The perceived shift in the presentation of dentine caries in permanent teeth (which seems to be getting harder to detect) responsible for this change is often attributed to the widespread use of fluoride toothpastes and the consequent increased mineral content of the enamel cusp slopes. Rather than have unsupported enamel fracture early to reveal a wide clinical cavity, in many cases lesions now progress more slowly and the well mineralised enamel stays in place overlying what can be slowly progressive 'hidden' dentine caries. ${ }^{12}$

More cohorts of children and young adults ${ }^{1,9}$ are moving to the stage of having large numbers of individuals with relatively low dentine caries levels, but a minority with a higher prevalence and incidence of dentine caries. The implication for routine practice is that, with the change in disease presentation seen in recent years, it is now becoming both more important and more difficult to tell which group a patient may belong to.

The 2003 Survey criteria were designed from the outset to allow results to be reported both with and without visual dentine caries (Fig. 1). The clear difference in results of the criteria change between the two dentitions is noteworthy. The findings for the permanent dentition are in accord with earlier work, but there are far fewer reports relating to these issues in primary teeth. Possible explanations for the lack of a difference are the typically faster caries progression rates seen in primary teeth as well as anatomical differences.

\section{Dental caries estimates in surveys related to findings in clinical practice}

Quite apart from the subtle differences in criteria for different types of dentine caries, there will also be inevitable differences between the results of survey examinations carried out in a school setting, using these type of criteria, and the findings which would be obtained by a clinician planning care for the same children in a dental surgery setting with access to compressed air, optimal lighting, including enamel caries in the clinical caries detection phase and using diagnostic aids such as radiographs and transillumination. These observations highlight the importance of recognising that children classified as having $d_{3 \mathrm{cv}} \mathrm{mft}=0$ or $\mathrm{D}_{3 \mathrm{cv}} \mathrm{MFT}=0$ in the survey are not 'free of disease' (Fig. 2b) or 'immune' from further caries attack and progression, particularly when considering the relentless increase in the mean prevalence of obvious dentine caries with age. The results of the survey should also be seen in the context of the changing care philosophies for dental caries which have seen both national and international moves away from an exclusively 'restorative' focus towards a more 'preventive' focus. ${ }^{3,5,11,13}$ The developments made in recent years by the International Caries Detection and Assessment System (ICDAS) Group ${ }^{7}$ will hopefully, in the future, provide an evidence-based framework to link the fields of epidemiology and clinical practice more closely, as well as facilitating future systematic reviews and knowledge transfer.

\section{Restoration of carious primary molars}

A final factor to consider in looking at the results from a clinical practice perspective is the question of whether or not the large number of primary molars seen with unrestored obvious dentine caries should have been restored. The issue of restoring (asymptomatic) carious primary molars has sparked an intense professional debate with strong advocates on both sides. On the one hand the clinical need to provide classical restorations for every decayed primary molar in every patient is being challenged with the option of giving preventive advice and 'leaving' the teeth apparently pain-free until exfoliation. On the other side advocates claim to be against such 'supervised neglect', and feel such a practice is missing an important opportunity to instil health, diet and hygiene habits at a key developmental stage of life, as well as voicing concerns about the risks of pain, sepsis and space loss. The debate is further complicated by the finding that some of the children with most disease are apparently rarely seen by any of the dental services. ${ }^{14}$ The survey findings cannot necessarily impact on either side of the debate, but they do provide a reliable population estimate of trends and of the 2003 situation.

\section{CONCLUSIONS}

The experience of obvious dentinal caries in children within the UK has continued to change over the last decade and the patterns observed are different for the permanent and primary dentitions. While continuing overall improvements are evident for permanent teeth in the specific age cohorts studied (eight, 12 and 15-year-olds), there have been no statistically significant improvements for mean values for the primary teeth of five or eight-year-olds and trends amongst those who have experience of dentinal caries are more concerning than for the population as a whole. The inclusion in the criteria of visual dentinal caries resulted in higher estimates of mean caries experience in the permanent but not the primary dentition. These survey results have implications for both planning and for daily practice, but both the trend data and the 2003 prevalence estimates must be interpreted carefully, acknowledging the specific survey conditions and caries criteria employed.

This work was undertaken by a consortium comprising the Office for National Statistics and the Dental Schools of the Universities of Birmingham, Cardiff, Dundee and Newcastle and the Dental Health Services Research Unit, Dundee who received funding from the United Kingdom Health Departments. The views expressed in this publication are those of the authors and not necessarily those of the Health Departments. Particular thanks are due to: all our colleagues within the Child Dental Health 2003 Consortium and the groups without whom the survey would not have taken place: the examining teams, the parents and their children for participating, the Schools and Education Authorities and the supporting UK Health Departments.

1. Pitts N B, Harker R. Obvious decay experience children's dental health in the United Kingdom 2003. Office for National Statistics October 2004 http://www.statistics.gov.uk/children/dental/health

2. Featherstone J D B. The continuum of dental caries - evidence for a dynamic disease process. J Dent Res 2004; 83: C39-C42.

3. Ismail A I, Hasson H. Sohn W. Dental caries in the second millennium. J Dent Ed 2001; 65: 953-959. 
4. Kidd E A M, Nyvad B. Caries control for the individual patient. In Fejerskov 0, Kidd E A M (Eds). Dental caries - The disease and its clinical management. pp 303-312. London: Blackwell Munksgaard, 2003.

5. Pitts N B. Are we ready to move from operative to non-operative/preventive treatment of dental caries in clinical practice? Caries Res 2004; 38: 294-304.

6. Pitts N B. Safeguarding the quality of epidemiological caries data at a time of changing disease patterns and evolving dental services. Comm Dent Health 1993 10: $1-9$

7. Pitts N B. 'ICDAS' - an international system for caries detection and assessment being developed to facilitate caries epidemiology, research and appropriate clinical management. Comm Dent Health 2004; 21: 193-198.

8. Pitts N B, Fyffe H E. The effect of varying diagnostic thresholds upon clinical caries data for a low prevalence group. J Dent Res 1988; 67: 592-596.
9. Office for National Statistics. Children's Dental Health Survey 2003 - Technical report, 2004. www.statistics.gov.uk/CHILDREN/dentalhealth

10. Pitts N B, Boyles J, Nugent Z J et al. The dental caries experience of 5-year-old children in England and Wales (2003/4) and in Scotland (2002/3). Surveys co-ordinated by the British Association for the Study of Community Dentistry. Comm Dent Health 2005; 22: 45-56.

11. Clinical Guideline 19. Dental recall: recall interval between routine dental examinations. National Institute for Clinical Excellence (NICE), Department of Health, London October 2004. www.nice.org.uk/CG019NICEguideline

12. Murray J J, Pitts N B. Trends in oral health. In Pine C M (Ed). Community ora health. pp 126-146. Oxford: Wright, 1997.

13. Tyas M J, Anusavice $\mathrm{K} J$, Frencken J E et al. Minimal intervention dentistry review. Int Dent J 2000; 50: 1-12.

14. Pitts N B. Do we understand about which children need and get appropriate dental care? Br Dent J 1997; 182: 273-278. 